Hartmann von Aue

Iwein

$\underset{D E}{G}$ 



\section{Hartmann von Aue}

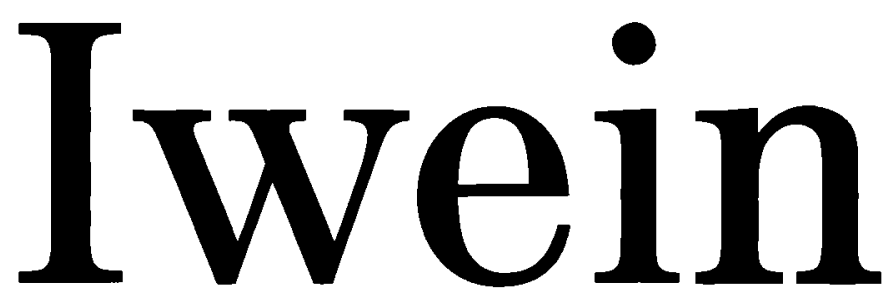

4., überarbeitete Auflage

Text der siebenten Ausgabe von

G. F. Benecke, K. Lachmann und L. Wolff

Übersetzung und Nachwort von

Thomas Cramer

\section{Walter de Gruyter · Berlin · New York 2001}


Der mhd. Text entstammt der Ausgabe „IWEIN. Eine Erzählung von Hartmann von Aue. Herausgegeben von G. F. Benecke und K. Lachmann. Neu bearbeiet von LUDWIG WOLFF. Berlin $1968^{\star}$.

Hartmann 〈von Aue〉:

Iwein / Hartmann von Aue. Text der siebenten Ausg. von G. F. Benecke ... Übers. und Nachw, von Thomas Cramer. - 4., überarb. Aufl. - Berlin ; New York : de Gruyter, 2001

ISBN 3-11-016084-6

(C) Copyright 2001 by Walter de Gruyter GmbH \& Co. KG, 10785 Berlin

Dieses Werk einschließlich aller seiner Teile ist wheberrechtlich geschützt. Jede Verwertung außerhalb der engen Grenzen des Urheberrechtsgesetzes ist ohne Zustimmung des Verlages unzulässig und strafbar. Das gilt insbesondere für Vervielfältigungen, Ubersetzungen, Mikroverfilmungen und die Einspeicherung und Verarbeitung in elektronischen Systemen.

Printed in Germany

Satz: Dörlemann Satz GmbH \& Co. KG, Lemförde

Druck und Bindung: Hubert \& Co. GmbH \& Co. KG, Göttingen 